\title{
HIV/AIDS-Related Knowledge and Behavior Among High School Students in A Less-Developed High-Risk Region: A Cross-Sectional Study
}

\section{Alireza Mohamadian}

Shiraz University of Medical Sciences

Hamid Sharifi

Kerman University of Medical Sciences

Jafar Hassanzadeh

Shiraz University of Medical Sciences

Mohsen Mohebbi-Nodezh

Hormozgan University of Medical Sciences

Mohammad Mohebbi-Nodezh

Hormozgan University of Medical Sciences

Hossein Molavi Vardanjani ( $\sim$ hosseinmolavi@ymail.com )

Shiraz University of Medical Sciences

\section{Research}

Keywords: Knowledge, Attitude, Practices, Behavior, HIV/AIDS, Students, Iran

Posted Date: October 9th, 2020

DOl: https://doi.org/10.21203/rs.3.rs-87136/v1

License: (9) (1) This work is licensed under a Creative Commons Attribution 4.0 International License. Read Full License 


\section{Abstract}

Background: Some residents of the Persian Gulf Coastline (PGC) areas are circular migrants due to geocommercial issues. They have a higher risk of HIV infection, lack of awareness, and non-disclosure of their HIV/AIDS status. These people who live with HIV (PLHIV) are considered as the bridge population for HIV transmission to general population, especially adolescents. This study sought to investigate the knowledge and behavior of adolescents about HIV/AIDS prevention and transmission in a less-developed high-risk area located along the PGC.

Methods: In this cross-sectional study using multistage cluster random sampling, 1450 students were invited to complete a standardized questionnaire. The prevalence of adequate knowledge, condom use, and stigmatization of HIV/AIDS and their 95\% Confidence Intervals (Cls) were estimated. Adjusted Odds Ratios (ORs) were estimated using ordinal logistic regression.

Results: Totally, $17.09 \%$ (Cl: 15.0-19.3) of the students had adequate knowledge. Social networks and the internet were the most important sources of information (20.9\%, Cl: 18.6-23.3). Socioeconomic status (OR: 2.0, 95\% Cl: 1.7-2.3), gender (0.6, Cl: 0.5- 0.8), residential area (0.08, Cl: 0.05-0.1), and using social networks and the internet as the main sources of information (1.5, Cl: 1.1-1.9) were correlated to the level of knowledge. Furthermore, 29.8\% (Cl: 27.2-32.5) of the students respected the social rights of PLHIV, and 12.6\% (Cl: 10.7-14.6) reported condom use.

Conclusion:HIV/AIDS-related educational programs are recommended in the PGC, especially for males, students from marginalized areas, and people with lower socioeconomic statuses. Social networks and the internet may be the most effective way to improve people's knowledge about HIV/AIDS.

\section{Plain English Summery}

In the border regions of southern Iran and north of the Arab countries, due to the geographical and commercial characteristics of the region, a significant percentage of residents are circular migrants. Since these populations are more likely to be HIV-infected, the risk of HIV transmission and its epidemics is significantly higher in these areas than in other areas. On average, less than one-fifth of Iranians aged 15-24 years have reported an adequate level of HIV/AIDS-related knowledge.

High school students, living in southern Iran, were asked to fill out the study questionnaire consisted of HIV/AIDSrelated questions concerning their knowledge, behavior and social stigma.

Out of 1450 students, 1194 persons accepted to participate. Among the participants, $17.1 \%$ of them had adequate knowledge levels about HIV/AIDS transmission and its prevention. The television, social networks and the internet were reported as the most common sources of information about HIV/AIDS. Less than one-third of students respected the social rights of people living with HIV to be valid and $12.6 \%$ of them reported condom use during their recent sexual intercourses.

Results showed that higher socioeconomic status, being female, being a resident of an urban area, seniority, and using Social Networks and Internet (SNI) as the main source of information were associated independently and positively with the students' knowledge levels. SNI could be used as the most effective way of communication 
with Iranian adolescents for health-related education. Finally, it was found to be urgent to reduce the level of HIV/AIDS stigmatization in these areas.

\section{Background}

The probability of infection with HIV in short-time migrants, especially circular ones, is significantly higher than in the normal population $(1,2)$. Although many factors contribute to this extra risk, one of the most important reasons may be the presence of more high-risk behaviors among these mobile people both in their origin and the destination of migration (1). Therefore, normal populations of origin and destination of circular migrants are at increased risk of becoming infected with HIV. Accordingly, such regions are highly vulnerable to HIV epidemics (3, 4).

In the border regions of southern Iran and north of the Arab countries, on the Persian Gulf coast, due to the geographical and commercial characteristics of the region, a significant percentage of residents, legally or illegally, are circular migrants. It has been estimated that $20-40 \%$ of these people are illegal immigrants (5). Since these high-risk behavior populations are more likely to be HIV-infected, the risk of intensified HIV transmission and consequently HIV epidemics is significantly higher in these areas than in other areas. On the other hand, despite the prohibition of extra-marital sexual relations in Iran, a significant proportion of Iranian teenagers have reported extra-marital sexual intercourse (6). However, these teenagers generally do not receive any education on safe sex and thus are more likely to have high-risk sexual behaviors. These social issues along with the changes of the predominant HIV transmission pattern in Iran (7), presence of anonymous carriers in the border areas of the Persian Gulf coast, and low levels of socio-demographic development (8) are alarming factors for a probable intensified transmission of HIV to adolescents living in these areas. Nonetheless, these teenagers do not have access to sexual healthcare centers or HIV/AIDS-related services because of cultural and legal prohibitions. The co-incidence of this lack of access, knowledge insufficiency, and unsafe behaviors can lead to an increased risk of HIV transmission (9). Given the cultural, legal, and religious restrictions for Iranian teenagers on having access to sexual health services, promotion of their HIV/AIDS-related knowledge and behaviors can be the most feasible and applicable preventive intervention in these areas (10).

The rate of HIV/AIDS-related knowledge among Iranians has been reported very differently across the country (11). Meanwhile, on average, less than one-fifth of Iranians aged 15-24 years have reported an adequate level of knowledge (12). Although there is no report on this proportion in border regions of the southern Iran, it may be reasonable to assume that this proportion is lower in such regions than in others. The present study aims to determine the level of knowledge and behavior of adolescents about HIV/AIDS in Bandar-Abbas and Hormuz Island located in the Persian Gulf coastline, in the south of Iran, as a high-risk population living in a less developed area.

\section{Methods}

\section{Design and sample}

This cross-sectional study was conducted in Bandar-Abbas $\left(27.1832^{\circ}\right.$ north and $56.2666^{\circ}$ East $)$ and Hormuz Island $\left(27.0593^{\circ}\right.$ north and $56.4608^{\circ}$ east) in southern Iran, with a coastline on the Persian Gulf, from January to March 2019. According to the latest Iranian census in 2016, the population of Bandar-Abbas and Hormuz Island 
was 680366 and 5891, respectively. In addition, male : female ratio was 1.04 and 0.99 in Bandar-Abbas and Hormuz Island, respectively $(13,14)$. Nearly $90 \%$ of the women in this region are literate $(15)$. Besides, one-fifth of the Bandar-Abbas population live in marginalized areas (13).

High school students in Bandar-Abbas and Hormuz Island were eligible to participate in the study. During a lecture, in the absence of the students' teachers, they were acquainted with the study and its objectives. Then, they were asked to fill out the study questionnaire if they wished. The students whose parents were not willing to participate in the study were not invited to attend the lecture. The students were informed that completing the questionnaire would represent consent to participate in the study.

With respect to a response rate of $75 \%$ due to the relative sensitivity of some questions, an assumed prevalence of $20 \%$ (the equivalent of the average national estimate) for desirable awareness, a precision of $15 \%$ prevalence (equivalent to $3 \%$ of estimated error), a sampling design effect of 1.6 , and type I error of 0.05 , a 1450 -subject sample size was determined.

Considering gender, city (Bandar-Abbas or Hormuz Island), municipal area, and students' educational grades as the sampling population's strata, a proportional to size multistage random cluster sampling was conducted. In each stratum, schools were selected as primary clusters. Then, classes in each selected school were randomly selected as final clusters. A total of 97 final clusters were randomly selected. In each cluster, 14-16 students were randomly selected by their number in the class list, excluding those whose parents were not willing to participate in the study. In the event of a student's dissatisfaction with participation in the study, another student was randomly selected and replaced.

\section{Data collection}

Data were collected using a validated self-administered questionnaire. The original version of the questionnaire for young Iranian population was considered (11), but some of the questions were removed, replaced, or corrected due to the concerns of the Local Education Department (Hormozgan Province Education Department). The reliability of the modified questionnaire was reevaluated. Its content validity was also re-evaluated and verified through experts' opinions. The modified questionnaire consisted of 22 knowledge questions (internal reliability of this section was evaluated using Cronbach's alpha, alpha $=0.792)$, two questions about behavior, one about social stigma, three about the participants' information resources about HIV/AIDS, five about the Socioeconomic Status (SES) of their families, four about their parents' occupations and education levels, and some questions about grade, age, and gender. They were also asked to score their truthfulness from 0-20 while completing the questionnaire.

\section{Data preparation and statistical analysis}

After entering the data into the software, $20 \%$ of the participants were randomly selected and their data were rechecked in terms of their consistency with the paper version of the questionnaires. Then, the data were prepared for statistical analysis using appropriate statistical techniques (16).

The participants were categorized into three groups based on their area of residence, including Hormuz Island, central areas of Bandar-Abbas, and marginalized areas of Bandar-Abbas, according to their school address. The SES of the participants was estimated using Multiple Correspondence Analysis (MCA) technique based on their 
self-reported monthly family income, level of education, parents' vocation, and location of their house and school. The participants were categorized into four groups according to the quartiles of SES scores provided by MCA.

Knowledge scores were estimated using the summation of the participants' scores. Then, the participants were classified into three categories, including weak level (scores less than or equal to 11), inadequate level (scores 12 to 16), and adequate level (scores greater than or equal to 17) based on their knowledge scores. Relative frequencies and their $95 \%$ confidence intervals as well as the mean score of knowledge and its Standard Deviation (SD) were used to describe the data.

Chi-square test was used to test the relationship among knowledge level, condom usage, perceived social stigma, and other qualitative variables. In addition, independent sample t-test and one-way Analysis of Variance (ANOVA) were used to assess the relationship between the knowledge score and other qualitative variables.

After assessing the proportionality assumption, ordinal logistic regression was used to evaluate the relationship between independent variables and knowledge level as the outcome variable. Independent variables with $p$-values less than 0.3 in bivariate analysis were selected as candidates for the multivariate analysis. Backward elimination technique was used to fit the model. A significant two-way statistical level was considered to be 0.05 . Data analysis was performed using Stata software (StataCorp., College Station, TX, USA).

\section{Results}

\section{Background data}

A total of 1450 high school students were invited to complete the questionnaires. out of this total, 1287 students accepted to participate in the study (participation rate was 89\%). However, 1194 questionnaires were completed and included in the analysis (the overall effective response rate was $82.3 \%$ ). The number of participants from Hormuz Island and Bandar-Abbas was 272 and 922, respectively. The mean age of the participants was 16.3 years $(S D=1.1$ years). The sex ratio (female: male) was 1.74:1 (Table 1$)$. 
Table 1

The relative frequency of the study participants according to their characteristics and knowledge levels

\begin{tabular}{|c|c|c|c|c|c|c|}
\hline \multirow[t]{3}{*}{ Variable } & \multirow[t]{3}{*}{ Stratum } & \multirow{2}{*}{\multicolumn{4}{|c|}{$\begin{array}{l}\text { Knowledge } \\
\text { (95\% Confidence Interval) }\end{array}$}} & \multirow{3}{*}{$\begin{array}{l}\text { P- } \\
\text { value }\end{array}$} \\
\hline & & & & & & \\
\hline & & n (\%) & Weak \% & $\begin{array}{l}\text { Inadequate } \\
\%\end{array}$ & $\begin{array}{l}\text { Adequate } \\
\%\end{array}$ & \\
\hline \multirow[t]{2}{*}{ Gender } & Female & $\begin{array}{l}758 \\
(63.5)\end{array}$ & $\begin{array}{l}25.3(22.2 \\
28.5)\end{array}$ & $\begin{array}{l}51.7(48.0, \\
55.3)\end{array}$ & $\begin{array}{l}22.9(20.0, \\
26.1)\end{array}$ & \multirow[t]{2}{*}{$.001>$} \\
\hline & Male & $\begin{array}{l}436 \\
(36.5)\end{array}$ & $\begin{array}{l}44.9(40.2 \\
49.7)\end{array}$ & $\begin{array}{l}48.1(43.3, \\
52.9)\end{array}$ & $\begin{array}{l}6.8(4.6 \\
9.6)\end{array}$ & \\
\hline \multirow[t]{3}{*}{ Residential area } & Hormuz Island & $\begin{array}{l}272 \\
(22.7)\end{array}$ & $\begin{array}{l}56.6(50.4 \\
62.5)\end{array}$ & $\begin{array}{l}39.7(33.8, \\
45.7)\end{array}$ & $\begin{array}{l}3.6(1.7 \\
6.6)\end{array}$ & \multirow[t]{3}{*}{$.001>$} \\
\hline & $\begin{array}{l}\text { Marginal areas of } \\
\text { Bandar-Abbas }\end{array}$ & $\begin{array}{l}318 \\
(26.6)\end{array}$ & $\begin{array}{l}45.2(39.7 \\
50.2)\end{array}$ & $\begin{array}{l}44.0(38.4, \\
49.6)\end{array}$ & $\begin{array}{l}10.6(7.5 \\
14.6)\end{array}$ & \\
\hline & $\begin{array}{l}\text { Central areas of } \\
\text { Bandar-Abbas }\end{array}$ & $\begin{array}{l}604 \\
(50.5)\end{array}$ & $\begin{array}{l}14.9(12.1 \\
17.9)\end{array}$ & $\begin{array}{l}58.6(54.5 \\
62.5)\end{array}$ & $\begin{array}{l}26.4(23.0 \\
30.2)\end{array}$ & \\
\hline \multirow[t]{7}{*}{$\begin{array}{l}\text { Main source of } \\
\text { knowledge }\end{array}$} & Television & $\begin{array}{l}386 \\
(32.3)\end{array}$ & $\begin{array}{l}27.9(23.5 \\
32.7)\end{array}$ & $\begin{array}{l}54.4(49.2 \\
59.4)\end{array}$ & $\begin{array}{l}17.6(13.9, \\
21.7)\end{array}$ & \multirow[t]{7}{*}{$.001>$} \\
\hline & Books & $\begin{array}{l}224 \\
(18.7)\end{array}$ & $\begin{array}{l}29.4(23.5, \\
35.9)\end{array}$ & $\begin{array}{l}55.3(48.5 \\
61.9)\end{array}$ & $\begin{array}{l}15.1(10.7 \\
20.5)\end{array}$ & \\
\hline & Teachers & $\begin{array}{l}154 \\
(12.9)\end{array}$ & $\begin{array}{l}44.1(36.1, \\
52.3)\end{array}$ & $\begin{array}{l}48.0(39.9, \\
56.2)\end{array}$ & $\begin{array}{l}7.7(4.0 \\
13.2)\end{array}$ & \\
\hline & Friends & $\begin{array}{l}60 \\
(5.0)\end{array}$ & $\begin{array}{l}33.3(21.6 \\
46.6)\end{array}$ & $\begin{array}{l}56.6(43.2 \\
69.4)\end{array}$ & $\begin{array}{l}10.0(3.7 \\
20.5)\end{array}$ & \\
\hline & $\begin{array}{l}\text { Social networks and } \\
\text { internet }\end{array}$ & $\begin{array}{l}250 \\
(20.9)\end{array}$ & $\begin{array}{l}26.4(21.0 \\
32.3)\end{array}$ & $\begin{array}{l}47.2(40.8 \\
53.5)\end{array}$ & $\begin{array}{l}26.4(21.0, \\
32.3)\end{array}$ & \\
\hline & Parents & $\begin{array}{l}24 \\
(2.0)\end{array}$ & $\begin{array}{l}50.0(22.1 \\
70.8)\end{array}$ & $\begin{array}{l}16.7(4.7 \\
37.3)\end{array}$ & $\begin{array}{l}33.3(15.6 \\
55.3)\end{array}$ & \\
\hline & Others & $\begin{array}{l}96 \\
(8.0)\end{array}$ & $\begin{array}{l}50.0(39.6 \\
60.3)\end{array}$ & $\begin{array}{l}39.5(29.7 \\
50.1)\end{array}$ & $\begin{array}{l}10.4(5.1 \\
18.3)\end{array}$ & \\
\hline \multirow[t]{2}{*}{$\begin{array}{l}\text { Participating in a } \\
\text { learning course }\end{array}$} & Yes & $\begin{array}{l}260 \\
(21.8)\end{array}$ & $\begin{array}{l}22.3(17.3 \\
27.8)\end{array}$ & $\begin{array}{l}56.9(50.6 \\
63.0)\end{array}$ & $\begin{array}{l}20.7(16.0, \\
26.2)\end{array}$ & \multirow[t]{2}{*}{$.001>$} \\
\hline & No & $\begin{array}{l}934 \\
(78.2)\end{array}$ & $\begin{array}{l}35.3(32.2 \\
38.4)\end{array}$ & $\begin{array}{l}48.6(45.3 \\
51.8)\end{array}$ & $\begin{array}{l}16.0(13.7 \\
16.5)\end{array}$ & \\
\hline
\end{tabular}

\section{The main sources of knowledge about HIV/AIDS transmission and prevention}

Television (32.3\%, 95\% Cl: 29.7, 35.1) and Social Networks and the Internet (SNI) $(20.9 \%, 95 \%$ Cl: 18.6, 23.3) were reported as the most common sources of information about HIV/AIDS. However, a few students (2.0\%, $95 \% \mathrm{Cl}$ : $1.2,2.9)$ reported that their parents were the most common sources of information for them. The prevalence of using SNI as the main source of information was $23.48 \%(95 \% \mathrm{Cl}: 20.5,26.7)$ for boys and $16.5 \%$ (95\% Cl: 13.2, 
20.3) for girls. The results showed a significant relationship between SES $(p<0.001)$ and gender $(p<0.001)$, maternal education level $(p<0.001)$, and residential area $(p<0.001)$.

\section{The participants' knowledge about HIV/AIDS transmission and prevention}

Among the participants, $17.1 \%$ (95\% Cl: 15.0, 19.3), 50.4\% (95\% Cl: 47.5, 53.3), and 32.5\% (95.1\% Cl: 29.8, 35.2) had adequate, inadequate, and weak knowledge levels about HIV/AIDS transmission and its prevention, respectively. In this regard, $23.0 \%$ of male students (95\% Cl: $20.0,26.1)$ and $6.9 \%$ of female ones $(95 \% \mathrm{Cl}: 4.7,9.7)$ had adequate knowledge levels $(p<0.001)$. The proportion of participants with adequate knowledge levels within the lowest and highest SES was estimated at 11.3\% (95\% Cl: 8.0,15.5) and $8.1 \%(95 \% \mathrm{Cl}: 5.2,11.8)$, respectively. Seniority $(p<0.001)$ and residential area $(p<0.001)$ showed a significant association with the adequate knowledge level (Table 1).

Among the study participants, 84.6\% (95\% Cl: 82.4, 86.6) and 83.2\% (95\% Cl: 80.9, 85.2) gave correct responses to questions about the possibility of HIV transmission through "sharing injection needles/syringes" and "sharing haircut kit of PLHIV", respectively. On the other hand, less than one-third of the students $(28.6 \%, \mathrm{Cl}: 26.0,31.2)$ gave correct answers to the question about "the possibility of transmission of HIV through mosquito bites". Additionally, slightly more than $30 \%$ of the participants $(30.8 \%, \mathrm{Cl}: 28.2,33.5) \mathrm{knew}$ that using oral contraceptive pills could not prevent HIV transmission (Table 2).

Table 2

The participants' knowledge on some modes of HIV transmission and prevention: items with the lowest correct responses

\begin{tabular}{ll}
\hline Statement & $\begin{array}{l}\text { Percentage of correct answers } \\
(95 \% \mathrm{Cl})\end{array}$ \\
\hline HIV can be transmitted through kissing PLHIV. & $63.0(60.2,65.7)$ \\
\hline HIV can be transmitted through swimming in a place where PLHIV swam. & $48.2(45.4,51.1)$ \\
$\begin{array}{l}\text { There is no way to reduce the possibility of HIV transmission through } \\
\text { penetrating sexual contact. }\end{array}$ & $36.9(34.1,39.6)$ \\
\hline $\begin{array}{l}\text { Using oral contraceptive pills reduces the transmission of HIV. } \\
\text { An HIV-infected mother can transmit the virus through her milk. }\end{array}$ & $30.8(28.2,33.5)$ \\
\hline Currently, there is no effective vaccine to provide protection against HIV. & $45.4(50.5,56.3)$ \\
\hline HIV can be transmitted through mosquito bites. & $28.6(26.1,31.3)$ \\
\hline
\end{tabular}

\section{Correlates of the participants' knowledge}

The results of bivariate analysis showed that paternal $(p<0.001)$ and maternal $(p<0.001)$ education levels were significantly associated with the students' knowledge. Moreover, knowledge level of the students living in urban areas of Bandar-Abbas was significantly higher compared to those living in rural areas $(p<0.001)$. Additionally, the knowledge level of the students in Hormuz Island was significantly lower compared to Bandar-Abbas residents $(p<0.001$; Table 1$)$. The results of multivariate ordinal logistic regression analysis showed that higher SES $(p<0.001)$, being female $(p<0.001)$, being a resident of Bandar-Abbas $(p<0.001)$, seniority $(p<0.001)$, and 
using SNI as the main source of information $(p=0.009)$ were associated independently and positively with the students' knowledge levels (Table 3).

Table 3

The correlates of adequate HIV/AIDS-related knowledge ${ }^{\star}$

\begin{tabular}{|lll|}
\hline Correlate & Crude OR (95\% Cl) & Adjusted OR (95\% Cl) \\
\hline Socioeconomic status (ordinal) & $0.94(0.86,1.04)$ & $1.97(1.69,2.30)$ \\
\hline $\begin{array}{l}\text { Knowledge source } \\
\text { (SNI: reference is the remaining sources) }\end{array}$ & $1.71(1.30,2.24)$ & $1.45(1.10,1.92)$ \\
\hline Residential area (HI: reference is BA) & $0.24(0.19,0.32)$ & $0.08(0.05,0.12)$ \\
\hline Gender (M: reference is F) & $0.37(0.29,0.46)$ & $0.60(0.46,0.79)$ \\
\hline Educational grade (ordinal) & $1.71(1.53,1.90)$ & $1.37(1.21,1.55)$ \\
\hline $\begin{array}{l}\text { Abbreviations: OR, Odds Ratio; Cl, Confidence Interval; SNI, Social Networks and Internet; HI, Hormuz Island; } \\
\text { BA, Bandar-Abbas; M, Male; F, Female }\end{array}$ & & \\
*Results of multivariable ordinal logistic regression & & \\
**Odds ratio for higher knowledge level compared with lower levels & \\
\hline
\end{tabular}

\section{Attitude towards HIV/AIDS and social stigma}

Less than one-third of students $(29.8 \%, 95 \% \mathrm{Cl}: 27.2,32.5)$ respected the social rights of PLHIV to be valid. This proportion was $40.4 \%(95 \% \mathrm{Cl}: 34.6,46.5)$ and $26.5 \%(95 \% \mathrm{Cl}: 23.6,29.4)$ among the students living in Hormuz Island and Bandar-Abbas, respectively ( $p<0.001)$. Moreover, $22.4 \%$ of the students with adequate levels of knowledge $(95.1 \% \mathrm{Cl}: 19.6,25.4)$ denied the social rights of PLHIV. Surprisingly, just $4.5 \%(95 \% \mathrm{Cl}: 2.6,7.2)$ of the students who respected the social rights of PLHIV had adequate levels of knowledge $(p<0.001)$.

\section{HIV/AIDS risk behavior}

According to the students' self-reports, nearly three-fourths of the students (74.5\%, 95\% $\mathrm{Cl}$ : 72.0, 77.0) had benefited from a method of protection against risky behaviors at least once in their lives. There was also a significant association between the students' knowledge levels and this perceived risk $(p<0.001)$.

Among the participants, $12.6 \%(95 \% \mathrm{Cl}: 10.7,14.6)$ reported condom use during their recent sexual intercourses. The results showed a significant difference between the individuals who had used condoms and those who had not regarding the mean score of knowledge $(14.1 \pm 3.9$ versus $12.7 \pm 4.0 ; p<0.001)$. The results also revealed a significant difference between girls and boys concerning the prevalence of condom usage (8.7\%, $95 \% \mathrm{Cl}: 6.80$, 10.95 versus $19.27 \%, 95 \% \mathrm{Cl}: 15.7,23.3 ; \mathrm{p}<0.001)$. This rate was found to be $4.4 \%(95 \% \mathrm{Cl}: 2.3,7.6)$ in Hormuz Island and 15.0\% (95\% Cl: 12.7, 17.4) in Bandar-Abbas $(p<0.001)$.

\section{Discussion}

In this study, high school students' knowledge levels and behaviors in relation to the prevention and transmission of HIV/AIDS were evaluated in a high-risk, less developed region with a circular population on the Persian Gulf border in southern Iran. The results indicated that less than one out of five students had adequate knowledge 
about HIV/AIDS prevention and transmission. Television and SNI were the most common sources of information for students. Furthermore, less than one-third of the students respected the social rights of PLHIV. Moreover, about $12 \%$ of the students reported using condoms during their recent sexual intercourses.

In this study, the ratio of males to females with adequate knowledge was about one to three. The conventionality of masculine perception of high-risk behaviors or a kind of prestige bias to do high-risk behaviors and lack of attention to precautions in low literacy areas may have led to the unwillingness of males with regard to the care training provided in a variety of ways. On the contrary, a similar study in northwestern Iran demonstrated that the ratio of males with high level of knowledge to females was close to seven (17). Significant differences have been obtained in this ratio in different regions of Iran (17). In another similar study conducted in Iraq, the neighbor of Iran, the number of males with high knowledge levels was significantly more in comparison to females (18). However, some studies have reported no gender differences in this regard (19).

Being resident in Bandar-Abbas, especially its non-marginal areas, was directly linked to an increase in the students' knowledge levels. Inadequacy of educational infrastructures in such underprivileged and less developed regions (with lower rates of literacy and unemployment) might have been associated with the students' behaviors and lower knowledge levels $(11,20)$. The families' lower SES in deprived areas could be another reason for this finding $(21,22)$. In a similar study conducted in Iraq, a significant difference was found between the less developed and more developed regions as well as between the families with higher and lower SES with respect to the proportion of people with adequate knowledge levels (18). These findings were in agreement with those of the present investigation. Coincidence of lower levels of knowledge with other risk factors for transmission, including more circular populations in these areas, poor access to healthcare, and poor healthcare utilization, may increase the risk of HIV/AIDS transmission in these areas.

Television, social networks, and the internet were the most common sources of information among the teenagers participating in the current study. Similarly, mass media, including television, were the most important sources of students' knowledge in other studies conducted in Bangladesh (23), India (24), and Iraq (18). Students who reported SNI as their main sources of information achieved an odd of 1.45 times of having an adequate level of knowledge compared to other students. The significance of this finding is that given the high influence of these networks on Iranians even in deprived areas, these networks can serve as a platform to promote the knowledge of Iranian teenagers (25). As parents were reported as the most important source of information for only 24 students (out of 1194), family-based interventions may not have acceptable effectiveness in such regions.

Although the students' knowledge on the possibility of transmission of HIV through sharing syringes and sharp objects was sufficient, their information on sexual transmission was not sufficient. In this context, only one-third of the students knew that there was at least one effective way to protect themselves from sexual transmission of the disease. This level of awareness was much lower compared to similar studies $(9,11,19)$. This might be attributed to the socio-cultural limitations for providing sex education.

In the present study, more than two-thirds of the students did not respect social rights for PLHIV, which could be a representation of social stigma in the region. This proportion was considerably higher in comparison to similar studies $(9,11,19)$. Researchers have highlighted the low level of knowledge as the reason of this high level of stigma $(19,26)$. Therefore, given the lower prevalence of adequate knowledge level in the current study, lack of knowledge among the participants might have caused higher levels of social stigma associated with HIV/AIDS in the study region. At the same time, the socio-cultural constraints and the guilt convictions of sexual intercourse in 
Iranian adult thoughts, especially in deprived areas, could be a structural factor in this respect (11). On the other hand, a significant proportion of the students stated television, which not only has all sociocultural and religious restrictions on content delivery, but also promotes these restrictions, as a source of information. High levels of social stigma can lead to lack of willingness to carry out HIV testing, thus concealing the infection and increasing the chance of its transmission to others (11). Therefore, efforts should be made to reduce the level of social stigma in such areas.

As to the participants' behaviors, $12.5 \%$ reported using condoms during their recent sexual intercourses. In the studies conducted in New Zealand, Malaysia, the United States, and Iran, about $30-50 \%$ of sexually active adolescents used condoms (27-30). Hence, it can be estimated that approximately $24-36 \%$ of the students participating in the present study had experienced at least one sexual contact. The proportion of condom users was roughly equivalent to that reported by other studies from similar communities $(27,28)$. While the marriage age in Iran is about a decade higher than the average age of the study students, most of them had possibly experienced extra-marital sexual relationships. Concealment of extra-marital sexual activities along with the lack of adequate access to and utilization of healthcare services can be a serious risk factor for these adolescents. Therefore, planning and immediate measures are necessary to provide adequate counseling and training for the students living in these areas in order to establish safe sexual contact.

The present study results revealed significantly higher knowledge levels among condom users compared to the others. In other words, the use of condom was greatly associated with the participants' knowledge levels. This was particularly important among the students in Hormuz Island who reported fewer cases of condom use as well as lower levels of knowledge. Similar results were also obtained in some other studies (9). Although females reported a lower proportion of condom use, they had a higher level of knowledge. This low level of condom usage by females might be due to their lower risky behaviors in comparison to males. In general, sexual activity occurs less in female gender in Iran (11).

\section{Conclusion}

The study results revealed inadequate levels of HIV/AIDS knowledge among the adolescents living in the Persian Gulf coastline areas of Iran. Males, students in less developed and marginal areas, and those living in families with lower SES were the most important groups to be considered for providing education in relation to HIV/AIDS transmission and prevention. SNI could be used as the most effective way of communication with Iranian adolescents for health-related education. Finally, it was found to be urgent to reduce the level of HIV/AIDS stigmatization in these areas.

\section{Study limitations}

One of the important limitations of this study was that it was not possible to directly ask the students about their high-risk behaviors, including questions about sexual contact and its type, due to legal and/or cultural sensitivities. In addition, it was not possible to identify the type of TV channels used by the students. The official television channels of Iran consider social and cultural limitations in presenting their contents, while other TV channels that are legally prohibited may not have these considerations. In any case, it seems that the TV contents (Iranian official TV and international channels) do not provide sufficient training in relation to sexual protection 
methods. However, this finding may not be generalizable to both types of TV channels. Finally, condom use might have been underestimated in the students' self-reports.

\section{Study strengths}

The adequacy of sample size and its representativeness were among the strengths of this study. This study was conducted for the first time in less developed regions of the Persian Gulf coastline in southern Iran. The results obtained from this study can be generalized to similar regions in Iran and other neighboring countries with similar characteristics, such as Persian Gulf Arab states.

\section{Abbreviations And Acronyms}

AIDS: Acquired Immunodeficiency Syndrome; BA: Bandar-Abbas; Cl: Confidence Interval; HI: Hormuz Island; HIV: Human Immunodeficiency Virus; MCA: Multiple Correspondence Analysis; OR: Odds Ratio; PGC: Persian Gulf Coastline; PLHIV: People Living with HIV; SD: Standard Deviation; SES: Socioeconomic Status; SNI: Social Networks and Internet

\section{Declarations}

\section{Ethics approval and consent to participate}

Before any contact with students, Hormozgan Provincial Education Administrative Office was formally contacted for getting permission to communicate with schools' principals, parents, and students. After a permit was issued, the principals of the selected schools were visited and the study was introduced to them. Then, an invitation was sent by the school principals to parents. The parents were asked to attend the school counseling sessions. During these counselling sessions, the study aims and procedures were presented in detail. In addition, the parents were asked to fill out informed consent forms if they were willing for their adolescents to participate in the study. The interested students were reassured that refusal to participate in the study would have no effects on their educational evaluations and that their information would be completely anonymous and would not be made available to school officials in an individualized format. They were also told to put their filled questionnaires in non-transparent boxes, which were designed to keep their information confidential. After completing the questionnaires, the students received a brochure consisting of essential information related to the prevention and transmission of HIV/AIDS. The steps and details of the study were approved by the Ethics Committee of Shiraz University of Medical Sciences (Approval code: SUMS.med.2019-368).

\section{Consent to publish}

Not applicable.

\section{Availability of data and materials}

The datasets used and/or analyzed during the current study are available from the corresponding author on reasonable request.

\section{Competing interests}

None declared. 


\section{Funding}

This study was funded by Shiraz University of Medical Sciences, the HIV/STI Surveillance Research Center, and WHO Collaborating Center for HIV surveillance, Institute for Future Studies in Health, Kerman University of Medical Sciences. They had no role in the design of the study and collection, analysis, and interpretation of data and also in writing the manuscript.

\section{Authors' contributions}

HMV suggested the idea of the research, designed the questionnaire, and contributed toward statistical analysis. ARM, HsMN and MdMN contributed toward data collection and writing the manuscript. HS and JHZ substantially contributed in proofreading and editing of the final manuscript. All authors have read and approved the final manuscript.

\section{Acknowledgements}

This study was conducted as a part of a thesis for simultaneous education in MD-MPH degree by ARM. Hereby, the authors would like to thank Ms. A. Keivanshekouh at the Research Improvement Center of Shiraz University of Medical Sciences for improving the use of English in the manuscript.

\section{Author details}

${ }^{1}$ MPH Department, Shiraz University of Medical Sciences, Shiraz, Iran. ${ }^{2}$ HIV/STI Surveillance Research Center, and WHO Collaborating Center for HIV Surveillance, Institute for Future Studies in Health, Kerman University of Medical Sciences, Kerman, Iran. ${ }^{3}$ Epidemiology Department, Shiraz University of Medical Sciences, Shiraz, Iran. ${ }^{4}$ Hormozgan University of Medical Sciences, Hormozgan, Iran

\section{References}

1. Olawore O, Tobian AAR, Kagaayi J, Bazaale JM, Nantume B, Kigozi G, et al. Migration and risk of HIV acquisition in Rakai, Uganda: a population-based cohort study. The lancet HIV. 2018;5(4):e181-e9.

2. Schuyler AC, Edelstein ZR, Mathur S, Sekasanvu J, Nalugoda F, Gray R, et al. Mobility among youth in Rakai, Uganda: Trends, characteristics, and associations with behavioural risk factors for HIV. Global public health. 2017;12(8):1033-50.

3. Camlin CS, Akullian A, Neilands TB, Getahun M, Bershteyn A, Ssali S, et al. Gendered dimensions of population mobility associated with HIV across three epidemics in rural Eastern Africa. Health \& Place. 2019;57:339-51.

4. Cassels S. Time, population mobility, and HIV transmission. The Lancet HIV. 2020;7(3):e151-e2.

5. Philippe Fargues FDB-A, Nasra M. Shah. Addressing Irregular Migration in the Gulf States2015 [cited 2019 Feb 25]. Available from: https://gulfmigration.org/media/pubs/briefs/GLMM\%20Policy\%20Brief\%20\%20No.\%201\%20-\%202015\%20-\%20Gulf\%20Irregular\%20Migration\%20-\%20Final.pdf.

6. Farahani FKA, Shah I, Cleland J, Mohammadi MR. Adolescent males and young females in tehran: differing perspectives, behaviors and needs for reproductive health and implications for gender sensitive interventions. Journal of reproduction \& infertility. 2012;13(2):101-10. 
7. Karamouzian M, Nasirian M, Sedaghat A, Haghdoost AA. HIV in Iran. Lancet (London, England). 2014;383(9922):1040.

8. Sabermahani A, Barouni M, Seyedin H, Aryankhesal A. Provincial human development index, a guide for efficiency level analysis: the case of iran. Iran J Public Health. 2013;42(2):149-57.

9. Thanavanh B, Harun-Or-Rashid M, Kasuya H, Sakamoto J. Knowledge, attitudes and practices regarding HIV/AIDS among male high school students in Lao People's Democratic Republic. Journal of the International AIDS Society. 2013;16:17387.

10. Tulloch HE, Balfour L, Kowal J, Tasca GA, Angel JB, Garber G, et al. HIV knowledge among Canadian-born and sub-Saharan African-born patients living with HIV. Journal of immigrant and minority health. 2012;14(1):132-9.

11. Shokoohi M, Karamouzian M, Mirzazadeh A, Haghdoost A, Rafierad A-A, Sedaghat A, et al. HIV Knowledge, Attitudes, and Practices of Young People in Iran: Findings of a National Population-Based Survey in 2013. PloS one. 2016;11(9):e0161849-e.

12. Joint United Nations Programme on HIV/AIDS. Islamic Republic of Iran 2016 [Available from: http://www.unaids.org/en/regionscountries/countries/islamicrepublicofiran.

13. Statistical center of Iran. Population and Household of the Country by Province and Sub-province 2016 [cited 2019 Feb 17]. Available from: https://www.amar.org.ir/Portals/1/census/2016/Population-and-Householdby-Province-and-Shahrestan.xlsx.

14. Statistical center of Iran. Population and Household of the Country (Hormozgan) 2016 [cited 2019 Feb 17]. Available from: https://www.amar.org.ir/Portals/0/census/1395/results/abadi/CN95_HouseholdPopulationVillage_22_r.xlsx.

15. Statistical center of Iran. Literacy in Hormozgan, Iran. 2018 [cited 2019 Feb 17]. Available from: https://hormozgan.mporg.ir/Pages/View/GoLink.aspx?Id=53d39458-d360-4e4e-94d79f65f468a91f\&ObjectType=File.

16. Molavi Vardajani H, Haghdoost AA, Shahravan A, Rad M. Cleansing and preparation of data for statistical analysis: A step necessary in oral health sciences research. Journal of Oral Health and Oral Epidemiology. 2016;5(4):171-85.

17. Malek A, Shafiee-Kandjani AR, Safaiyan A, Abbasi-Shokoohi H. Sexual Knowledge among High School Students in Northwestern Iran. ISRN pediatrics. 2012;2012:645103.

18. Othman SM. Knowledge about HIV/AIDS among high school students in Erbil city/Iraq. Global journal of health science. 2015;7(1):16-23.

19. Nubed CK, Akoachere J-FTK. Knowledge, attitudes and practices regarding HIV/AIDS among senior secondary school students in Fako Division, South West Region, Cameroon. BMC Public Health. 2016;16(1):847.

20. Zarei E, Khabiri R, Tajvar M, Nosratnejad S. Knowledge of and attitudes toward HIV/AIDS among Iranian women. Epidemiology and health. 2018;40:e2018037.

21. Sanchez ZM, Nappo SA, Cruz JI, Carlini EA, Carlini CM, Martins SS. Sexual behavior among high school students in Brazil: alcohol consumption and legal and illegal drug use associated with unprotected sex. Clinics (Sao Paulo, Brazil). 2013;68(4):489-94. 
22. Tee $Y$, Huang M. Knowledge of HIV/AIDS and attitudes towards people living with HIV among the general staff of a public university in Malaysia. SAHARA J : journal of Social Aspects of HIV/AIDS Research Alliance. 2009;6(4):179-87.

23. Huda MN, Amanullah AJAilD. HIV/AIDS-Related knowledge among secondary school students in Bangladesh: a cross-sectional study. 2013;3(04):274.

24. Gupta P, Anjum F, Bhardwaj P, Srivastav J, Zaidi ZH. Knowledge About HIV/AIDS Among Secondary School Students. North American journal of medical sciences. 2013;5(2):119-23.

25. Internet World Stats. Iran Internet usage, broadband and telecommunications reports 2017 [cited 2019 April 27]. Available from: https://www.internetworldstats.com/me/ir.htm.

26. Haroun D, El Saleh O, Wood L, Mechli R, Al Marzouqi N, Anouti S. Assessing Knowledge of, and Attitudes to, HIV/AIDS among University Students in the United Arab Emirates. PloS one. 2016;11(2):e0149920.

27. Ahmad N, Awaluddin SM, Ismail H, Samad R, NikAbdRashid N. Sexual activity among Malaysian schoolgoing adolescents: what are the risk and protective factors? Asia-Pacific journal of public health. 2014;26(5 Suppl):44s-52s.

28. Clark TC, Lucassen MF, Fleming T, Peiris-John R, Ikihele A, Teevale T, et al. Changes in the sexual health behaviours of New Zealand secondary school students, 2001-2012: findings from a national survey series. Australian and New Zealand journal of public health. 2016;40(4):329-36.

29. Hosseini Hooshyar S, Karamouzian M, Mirzazadeh A, Haghdoost AA, Sharifi H, Shokoohi M. Condom Use and its Associated Factors Among Iranian Youth: Results From a Population-Based Study. International journal of health policy and management. 2018;7(11):1007-14.

30. Martinez GM, Abma JC. Sexual Activity, Contraceptive Use, and Childbearing of Teenagers Aged 15-19 in the United States. NCHS data brief. 2015(209):1-8. 